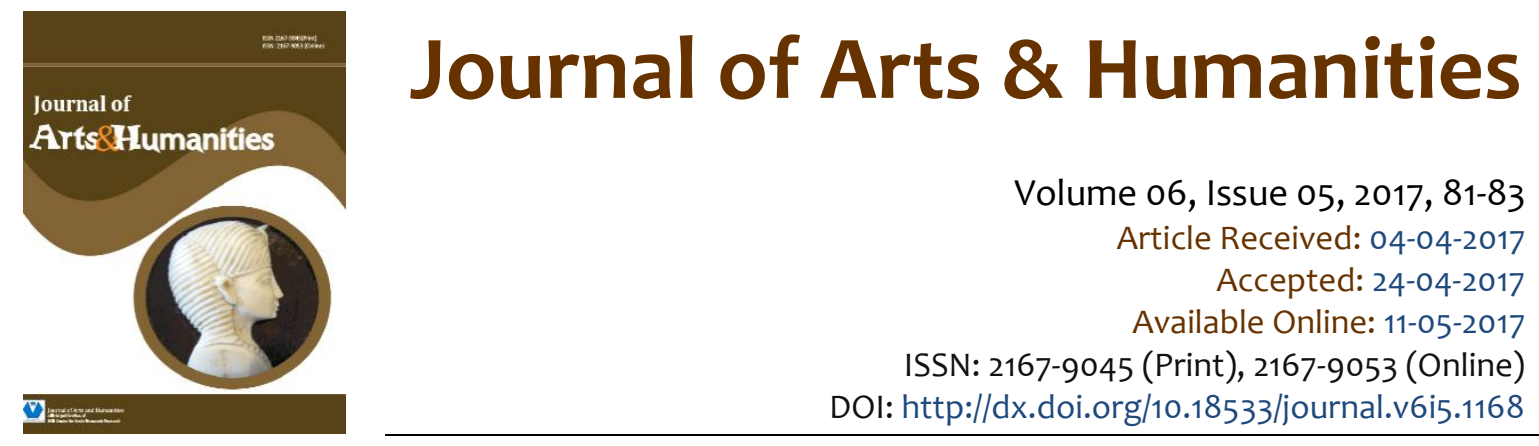

\title{
Jewelry Design under Environmental Protection Concept
}

\author{
Jinjin-Ma', Yue-Hu' ${ }^{1}$
}

\begin{abstract}
As people living standard unceasing enhancement, jewelry has been more and more into our modern life. Jewelry is not simply to use gold, platinum, silver and other precious metals as the material, but joined a variety of materials for production, to fully display the wearer's personality. Jewelry is not only a symbol of wealth, she has become us to highlight the carrier of its own unique personality and identity.
\end{abstract}

Keywords: Environmental protection, Jewelry, Wood.

This is an open access article under Creative Commons Attribution 4.0 License.

Jewelry is often referred to as small sculpture, sculpture on the modelling is very exquisite space feeling, at this point, jewelry and sculpture is interlinked. Jewelry than large sculpture is exquisite and meticulous, it is not just a simple, cold work, is way into the feelings and emotions. In the 2oth century, especially after the middle of the 2oth century, the rapid development of advanced science and technology, has led to various new ideas emerge in endlessly, so demand for personalized jewelry design and originality is becoming more and more high. Personalized jewelry, eccentricity, and jewelry worn and display effect is the focus of modern people attach importance to concise, abstract and stereoscopic jewelry instead of the usual tedious, complicated and delicate jewelry. At the same time, the jewelry is not just the accessories, it has deep into our spirit of self expression of a kind of carrier, it also requires modern jewelry has the characteristics of humanization. The development of modern social culture makes the appearance of modern jewelry and material use, great changes have taken place in ceramic, wood, shells, coral, tiger, enamel, plastics, leather and paper for more materials used in jewelry design and production. A variety of materials in the application of jewelry, also make us have more free space. In jewelry design and production should not only considering the practicality of the wear resistance, also should consider its aesthetic modelling namely. When considering its practicality, from material choosing, external shape! Considering, decoration, etc. Jewelry in the performance of the aesthetic focus for modelling beauty. Therefore attach great importance to the design of the modelling of jewelry design, and try to explore the potential of materials and decoration, pay attention to use a variety of forms such as colour, line, shape factor, and exaggeration, deformation, balanced and

\footnotetext{
1 Shanghai University of Engineering Science, Shanghai, P.R. China, 21600. Email: mjj120629317@163.com
} 
various artistic techniques, to create the appearance of the jewelry formal beauty. Jewelry also belong to a kind of arts and crafts, arts and crafts than other art categories, more directly affected by the material and production technology, so need more rigorous artistic conception.

Wooden decorations, either from the perspective of external form or its deep connotation is the unity of the human material pursuit and spiritual pursuit. It not only satisfy people's aesthetic demands, use, and combines the era connotation and cultural features. Decoration as the main purpose of wooden adorn article focuses on the function of aesthetic at the same time, can't ignore the correlation of beauty and culture, human nature, should also pay attention to improve cultural connotation and cultural characteristic of wood accessories. Wooden jewelry design is wooden jewelry aesthetic art performance of the main aspects, which including shape, color, design elements such as idea, it belongs to design category of beauty. Its decoration technique is a means of various desired decorative purposes, it includes two aspects of molding process and surface decoration techniques. Wooden jewelry selection is the first step for the implementation of technical elements, different materials, its texture, texture, luster is different. For the birch wood accessories commonly used three joint form joint, glue joint and metal fittings, different joint forms result in different adornment effect. In "structured adornment" as the theme of today, wooden jewelry structure form in the future will be toward the superposition, restructuring, bundling, accumulation, devices, and other more innovative, a form unique development. Wooden jewelry design innovation is a powerful means of enhance competitiveness of the wooden ornaments, wooden jewelry design innovation methods including morphological innovation, material innovation, structure innovation, culture and brand, they are concrete measures to realize wooden jewelry design innovation. In the design of traditional wooden jewelry, natural wood is the main material, people often make use of the advantages of lumber itself to annotation act the role ofing is tasted. Beautiful natural wood texture, colour and lustre is natural, wood soft hard moderate, is a good decoration material. Appeared during the Ming and qing dynasties, a large number of home decoration kits, screen, decorative boxes, and study appliance, etc., mostly with certain function desk curios. They are not so much a appliance, as a fine piece of art. Ancient wooden jewelry design by builders to judge its material, on the wood carving, chisel, painting, printing, spraying, etc all by exquisite craftsmanship, also left a lot of beautiful for future generations. Modern wooden jewelry design, the emergence of various new compound wood material, and production equipment update and also for the wooden jewelry new production processes and new decorative techniques has opened up a new way.

The jewelry design (As shown in figure) inspiration from the nature round place, use the technique of the superposition of restructuring for secondary processing of wood jewelry production. "Nature round place" is an ancient scientific understanding of the universe, its essence is originated from the evolution of the innate gossip, the driving performance of heaven and earth, namely: figure nature round place. The

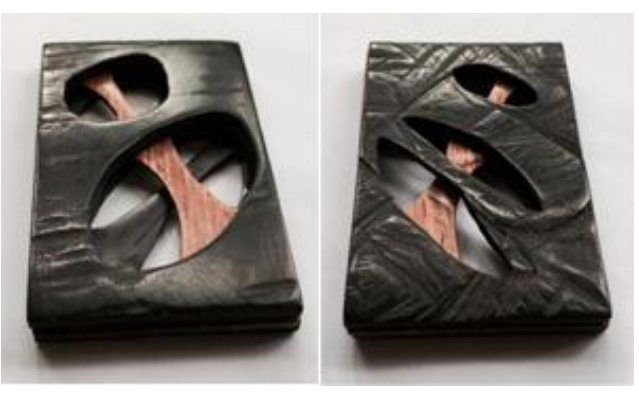
Numbers outside the enclosure, on behalf of day works, and the middle square array of Numbers, represents the works. Among them, the day is the master, it is time, day for Yang and Yin. Both mutual induction, created the universe, including man it is the essence of heaven and earth material, thus is regarded as the soul of the universe of heaven and earth, able to sense things, also the spirit. The Taoist thought: "sky" mind in harmony to access; "Local" life to strict regulations. Chinese han nationality traditional culture advocates the "nature and humanity", pay attention to imitate nature, geomantic art in esteem the principle of "nature round place", is a special note to this kind of cosmology. Material selection of color differences in the degree of two kinds of rosewood, the crisscross hollow out and stack. Shape is square, the main hollow out the graph is circular, produce different after mutual crisscross pattern. Obtained from the image of the jewelry decoration effect, simple, abstract, three-dimensional modelling conforms to the contemporary spirit of restoring ancient ways is accompanied by relying on the complex society. Between the combination of beauty and materials and the organic unity of skillfully using material itself unique aesthetic feeling, enhance the aesthetic characteristics, the application of environmental protection material is new trend of development of 
the future of jewelry.

\section{Reference}

Shao Min. Contemporary Jewelry Design against the Art Nouveau[J].Journal of Shenzhen University(Humanities \& Social Sciences),2012, 29(1).

Li Lu. "Concept" in contemporary jewelry design creation concept study[D].Beijing institute of fashion technology,2015.

ZHang Zhaojuan. Fashion research of modern jewelry design[D]. Wuhan university of technology,2008.

$\mathrm{Xu}$ Wenyue. Is the result of natural jewelry design ideas[D].China university of geosciences (Beijing),2010.

Liu Fang. Exploring theory of jewelry of nature - the use of natural elements in the design of jewelry[D],Suzhou university,2008. 